\title{
Symptomatic giant bone island of the tibia mimicking lesion of the medial meniscus
}

\author{
Alexander Schuh ${ }^{1 *}$, Ralph Schuh ${ }^{2}$, Albert Fujak ${ }^{3}$, Wolfgang Hönle ${ }^{1}$ and Sandeep Kashyap ${ }^{4}$ \\ ${ }^{1}$ Musculoskeletal Center, Neumarkt Hospital, 92318 Neumarkt, Germany \\ ${ }^{2}$ Orth.Med Weiden, 92637 Weiden, Germany \\ ${ }^{3}$ Department of Orthopaedics, University of Erlangen-Nurenberg, Erlangen, Germany \\ ${ }^{4}$ Postgraduate Institute of Medical Education \& Research, Chandigarh, India
}

\begin{abstract}
Bone island represents a focus of mature compact bone within the cancellous bone. A giant bone island is defined as having a diameter greater than 2 cm, it's a rare condition and usually asymptomatic. We report the case of a 41-year-old male patient with a symptomatic giant bone island of the tibia mimicking a lesion of the medial meniscus.
\end{abstract}

\section{Introduction}

Bone island, also termed enostosis, is a focal intraosseous mass of compact lamellar bone with Haversian systems, which blends into the surrounding cancellous bone [1]. Most lesions are between 2 $\mathrm{mm}$ and $2 \mathrm{~cm}$ in size and are located in the juxtaarticular regions of long bones, oriented along the long axis of the bone. It is difficult to determine the prevalence of bone islands; however, they are extremely common and seen with equal frequency in men and women. Bone islands as hamartomatous malformations in the bone are known to be asymptomatic in nature [2,3]. A giant bone island, defined as having a diameter greater than $2 \mathrm{~cm}$, has been rarely reported $[2,4-10,11]$. We report the case of a 41-year-old male patient with a symptomatic giant bone island of the tibia mimicking a lesion of the medial meniscus.

\section{Case report}

A 41-year-old man suffered from persisting pain of the popliteal fossa of the left knee. 4 weeks before arthroscopy and partial resection of the medial meniscus due to a mensical tear was performed elsewhere without relief of symptoms. Physical examination revealed a free range of motion of the left knee with Extension/ Flexion $5 / 0 / 140^{\circ}$. Collateral and cruciate ligaments were stable, meniscus signs were negative, there was no effusion, scars where normal, too. $\mathrm{X}$ ray of the left knee in two planes showed a $5 \times 7 \times 3 \mathrm{~cm}$ intracortical dense bone tumour with an unsharp border without periostal reaction signs (Figure 1). MRI scan of the left knee showed edema surrounding the tumour. There were no signs of malignancy (Figure 2a). CT scan revealed the extent of the tumour reaching the subchondral bone of the medial tibial head (Figure $2 b)$. To clarify dignity of the bony lesion open biopsy was performed. One day later the patient was out of any pain. Histologic examination led to the diagnosis of a giant bone island. The patient was anxious about recurrence of the symptoms and wished complete resection of the giant bone island. We performed complete resection of the giant bone island with a massive bone transplantation from our bone bank, stabilizing the proximal tibia with a fixed angle plate and a K- wire (Figure 3). 8 weeks later the patient developed CRPS 1. After intensive physiotherapy and medical therapy there was a relief of discomfort in regard to CRPS 1.1 year later removal of the plate was performed. Latest follow- up after 5 years was out of any complaints, there was a free range of motion of the left knee (Figure 4), x-ray showed no signs of recurrence.
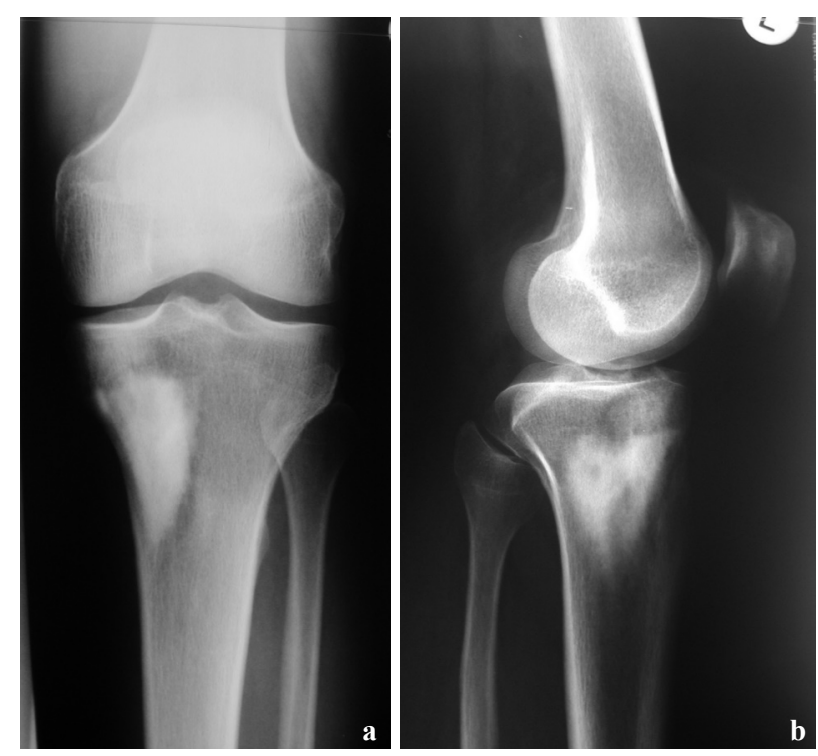

Figure 1. X ray of the left knee -a.p. a. and lateral; b. view- shows a 5 × 7 × $3 \mathrm{~cm}$ intracortical dense bone tumour with an unsharp border without periostal reaction signs.

Correspondence to: Dr.med.habil.Alexander Schuh, Head of Musculoskeletal Center, Neumarkt Hospital, Teaching Hospital of the University of ErlangenNurenberg, Nürnberger Str. 1292318 Neumarkt i.d. Opf, Germany, Tel: +499181-420-3500; Fax: +49-9181-420-3503; E-mail: Alexander.Schuh@klinikum. neumarkt.de

Received: February 06, 2018; Accepted: February 20, 2018; Published: February 26,2018 


\section{Discussion}

A bone island represents a focus of mature compact bone within the cancellous bone, and it can be diagnosed based on characteristic clinical and radiologic features. The lesion is typically asymptomatic with a preference for the pelvis, femur, and other long bones. On radiographs, the lesion appears as an ovoid, round or oblong homogeneously dense and sclerotic focus in the cancellous bone. The characteristic features of this lesion are radiating bony streaks, known as thorny radiations or pseudopodia. Most bone islands are small, and the majority of these lesions measure from 0.1 to $2.0 \mathrm{~cm} \mathrm{[2].} \mathrm{A} \mathrm{giant}$ bone island, defined as having a diameter greater than $2 \mathrm{~cm}$, has been rarely reported $[2,4-10,11]$. Symptomatic giant bone island of the

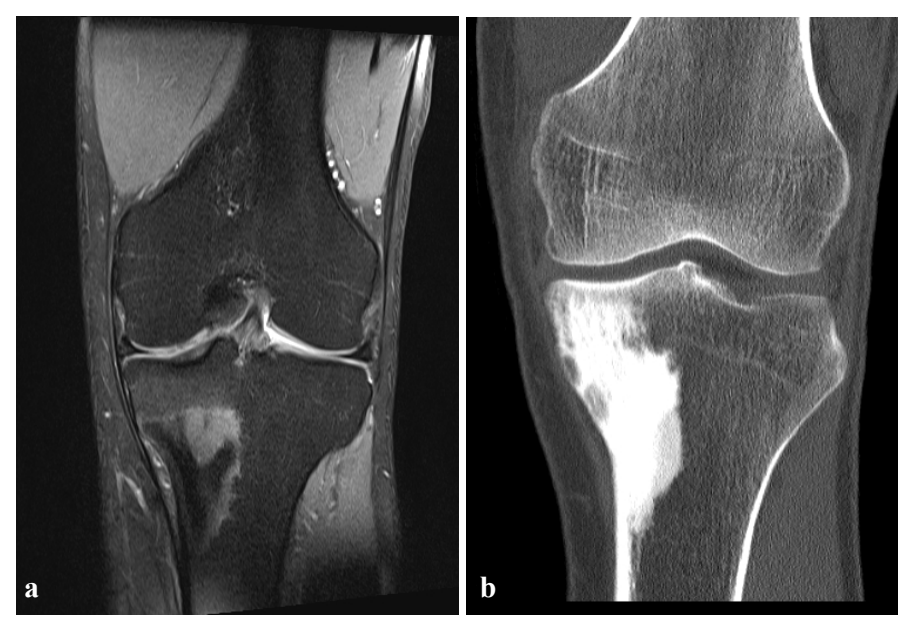

Figure 2. a. MRI of the left knee shows edema surrounding the tumour. There are no signs of malignancy; b. CT scan reveals the extent of the tumour just below the subchondral bone of the medial tibial head.

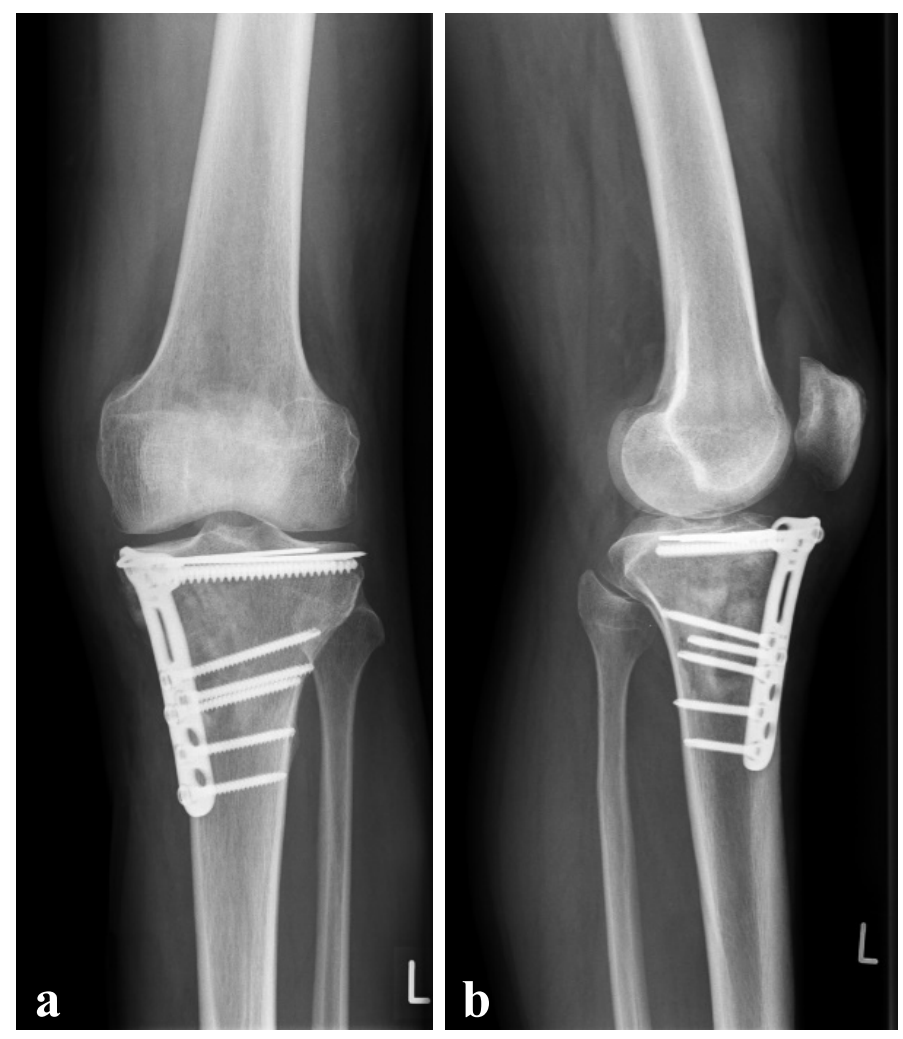

Figure 3. $X$ ray of the left knee -a.p. a. and lateral; b. view- two weeks after resection of the giant bone island shows fixed-angle plate osteosynthesis and an additional K-wire.
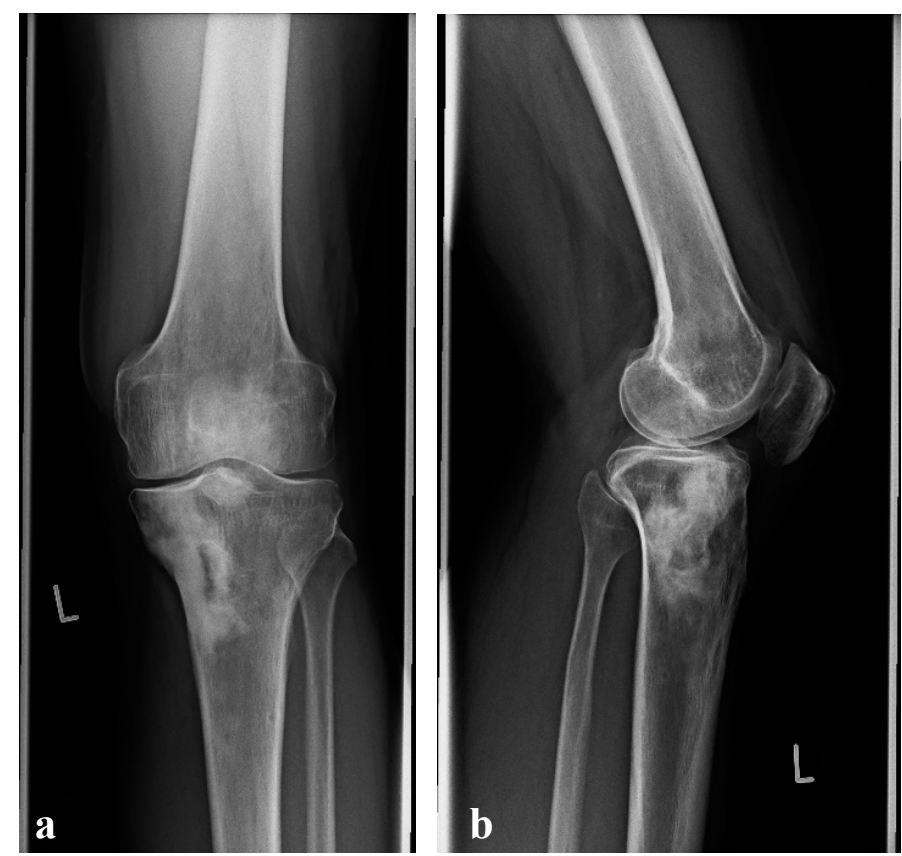

Figure 4. $\mathrm{X}$ ray of the left knee -a.p. a. and lateral; b. view- 4 years after removal of the plate and screws reveals a small central bony defect but no signs of recurrence.

tibia is a rare condition and has been described recently [2]. For nearly three quarters of a century bone islands (enostoses) were considered scintigraphically inactive, hence, easily differentiated radiologically from clinically more significant primary or metastatic intraosseous lesions. However, enostoses' clinical significance has changed considerably since the first report of a case with increased radioactive uptake on bone scan in 1976 [6]. Caballes et al. [6] described the case of a 23-year-old woman presented with polyostotic enostoses discovered incidentally during pelvic radiographic examination. Both scintiscan and skeletal survey identified one or three fairly large densely radiopaque lesions in many bones, the largest measuring $7 \mathrm{x} 4 \mathrm{~cm}$. In absence of definitive roentgenologic diagnosis, both needle and open biopsies were performed. We follow other authors that diagnosis of a giant bone island is a radiologic one. Although bone islands are a well-known benign skeletal entity, it may stimulate an aggressive bone forming neoplasm when it is large. Spiculated margin intermingling with thickened trabeculae together with the lack of bone destruction and soft tissue mass on computed tomography scan is diagnostic [2]. In unclear cases we also recommend open biopsy [5,6,11] to clear differential diagnosis including osteoidosteoma, osteopoikilosis, osteopathia striata or sclerotic osteosarcoma. In our case MRI was performed before arthroscopy to proof the suspected diagnosis of a tear of the medial meniscus. At that time edema surrounding the giant bone island could be detected. Retrospectevly this was a hint for symptomatic giant bone island. In our case the patient was out of pain after open biopsy. The patient was anxious about recurrence of the symptoms and wished complete resection of the giant bone island. Dhaon BK et al. [7] described two cases of giant bone island of femur complicating total knee replacement. In one case, giant bone island led to fracture of the medial part of the cortex, which was fixed with a screw prior to insertion of the prosthesis. In the second case, a window was made in the femur to remove hard bone sufficient for insertion of the prosthesis. These cases illustrate the problems that can be encountered during surgery in the presence of bone islands. We believe that complete resection of the giant bone island is not absolutely necessary but should be discussed frankly with the patient in respect to later surgeries, especially in the region of larger joints like the knee. 


\section{References}

1. Mirra JM (1989) Bone tumors: clinical, radiologic and pathologic correlations. Philadelphia: Lea \& Febiger: 143-438.

2. Park HS, Kim JR, Lee SY, Jang KY (2005) Symptomatic giant $(10-\mathrm{cm})$ bone island of the tibia. Skeletal Radiol 34: 347-50. [Crossref]

3. Resnick D, Kyriakos M, Greenway GD (2002) Tumor and tumor-like lesions of bone: imaging of specific lesions. In: Resnick D, editor. Diagnosis of bone and joint disorders. 4th edition. Philadelphia: W.B. Saunders: 3763-4128.

4. A very GR, Wilsdon JB, Malcolm AJ (1995) Giant bone island with some central resorption. Skeletal Radiol 24: 59-60. [Crossref]

5. Brien EW, Mirra JM, Latanza L, Fedenko A, Luck J Jr (1995) Giant bone island of femur. Case report, literature review, and its distinction from low grade osteosarcoma. Skeletal Radiol 24: 546-550. [Crossref]
6. Caballes RL, Caballes RA Jr (2004) Polyostotic giant enostoses with strongly positive radionuclide bone scan. Ann Diagn Pathol 8: 247-251. [Crossref]

7. Dhaon BK, Gautam VK, Jain P, Jaiswal A, Nigam (2004) Giant bone island of femur complicating replacement arthroplasty: a report of two cases. J Surg Orthop Adv 13: 220-223. [Crossref]

8. Ehara S, Kattapuram SV, Rosenberg AE (1989) Giant bone island. Computed tomography findings. Clin Imaging 13: 231-233. [Crossref]

9. Gold RH, Mirra JM, Remotti F, Pignatti G (1989) Case report 527: Giant bone island of tibia. Skeletal Radiol 18: 129-132. [Crossref]

10. Ikeuchi M, Komatsu M, Tani T (2010) Giant bone island of femur with femoral head necrosis: a case report. Arch Orthop Trauma Surg 130: 447-450. [Crossref]

11. Trombetti A, Noël E (2002) Giant bone islands: a case with 31 years of follow-up. Joint Bone Spine 69: 81-84. [Crossref]

Copyright: $\odot 2018$ Schuh A. This is an open-access article distributed under the terms of the Creative Commons Attribution License, which permits unrestricted use, distribution, and reproduction in any medium, provided the original author and source are credited. 